\title{
Comparison on the Word Stress Patterns and Functions between English and Sichuan Dialect
}

\author{
Chuandong Ma1, Lunhua Tan ${ }^{2 *}$ \\ ${ }^{1}$ College of Fundamental Education, Sichuan Normal University, Chengdu, China \\ ${ }^{2}$ Sichuan Staff University of Science and Technology, Chengdu, China \\ Email: machuandong2006@163.com, tan-lunhua@sohu.com
}

Received 7 September 2015; accepted 9 October 2015; published 14 October 2015

Copyright (C) 2015 by authors and Scientific Research Publishing Inc.

This work is licensed under the Creative Commons Attribution International License (CC BY).

http://creativecommons.org/licenses/by/4.0/

(c) (i)

\section{Abstract}

Word stress is one of the most important elements in phonology, accompanied by segmental phonemes to express certain meaning of vocabulary, grammar, etc. Although both English and Chinese belong to free stress languages, most of the English words are polysyllabic, and their compositions are complicated, besides, its vocabulary is mixed with a large number of foreign words, thereby causing the complexity and irregularity of the English word stress patterns. In contrast, most words in Sichuan dialect are disyllabic and only some are trisyllabic or more than three syllables, thus the word stress patterns in Sichuan dialect are much simpler than English. In addition, judging from the functions of word stress, it plays a more important role in English than in Sichuan dialect, which can not only distinguish meanings, differentiate compound words from adjective phrases, but also discriminate the part of speech of some disyllabic words with the same spelling. This article will make a comparative study on the word stress between English and Sichuan dialect from their natures, patterns and functions, and summarize the similarities and differences of them. It aims to be of helpful to students in dialect area in learning English pronunciation and help them avoid misplacing word stress in communication.

\section{Keywords}

Comparison, English, Sichuan Dialect, Word Stress Pattern, Function

\section{Introduction}

Stress is a very important part in the phonetic structure of English, and it also has the function of distinguishing

${ }^{*}$ Corresponding author. 
meanings or part of speech in the words or phrases with the same phonemes. Intonation and rhythm in English are based on stress, which are very important ways of expressing meanings. Chinese is a tone language and stress does not play so important a part as it does in English, but it also has the function of distinguishing meanings. The basic characteristics of English and Chinese stress are the same, and they both rely on the four factors: the sound intensity, duration, pitch and timbre to play a role in distinguishing meanings. But in English, pitch is the most important factor, while timbre is the least important. In Chinese, the most important factor is duration, and intensity is the least. As for their functions, stress can distinguish compound nouns from phrases both in English and Chinese, but stress does not distinguish part of speech of words in Chinese. Judging from their word stress patterns, English is much more complicated than those in Chinese (Xi Xiaoming, 1990) [1]. In this paper, we will mainly discuss on the differences and similarities of the features and functions of word stress in English and Sichuan dialect. Up till now, there isn’t any research regarding the comparison on the word stress patterns and functions of the two languages.

\section{The Differences between English and Sichuan Dialect in Their Stress Patterns}

\subsection{The Features of the Word Stress Patterns in English}

The word stress patterns in English are free and complicated. English linguist A. C. Gimson once defined English word stress as follow: The accentual pattern of English words is fixed, in the sense that the main stress always falls on a particular syllable of any given words, but free, in the sense that the main stress is not tied to any particular situation in the chain of syllables constituting a word, as it is in some languages. The stress may fall on the first, second or third, sometimes on the fourth syllable (A. C. Gimson, 1972: p. 222) [2]. He summarized the word stress patterns of English words with two to seven or eight syllables, and there are totally thirty-five different patterns. In addition, the compound words in English also have different stress patterns.

\section{The stress patterns of single word:}

\section{Two syllables:}

Middle-Strong: unknown, Chinese, thirteen, canteen, cashier;

Weak-Strong: alone, machine, arrive, behind, invent, reform;

Strong-Weak: over, under husband, cotton, table, valley, rhythm;

Strong-Middle: profile, placard, program , window.

\section{Three Syllables:}

Middle-Weak-Strong: understand, cigarette, magazine, entertain, personnel, seventeen;

Strong-Weak-Weak: quantity, yesterday, innocence, bachelor, wanderer;

Strong-Weak-Middle: appetite, pedigree, photograph, cataract, telephone;

Weak-Strong-Weak: important, encounter, excessive, relation, eleven;

Middle-Strong-Weak: uncertain, re-entry, foreknowledge;

Weak- Strong-Middle: tobacco, tomato, embargo, prehensile.

\section{Four Syllables:}

Weak-Strong-Weak-Weak: remarkable, impossible, affirmative, establishment, photography;

Middle-Strong-Weak-Weak: unfortunate, rhinoceros, diocesan;

Weak-Strong-Weak-Middle: acetylene, acclimatize, enumerate;

Middle-Weak-Strong-Weak: unimportant, insufficient, circulation, diplomatic, photographic;

Strong-Weak-Weak-Weak: cowardliness, melancholy, caterpillar, criticism;

Strong-Weak-Middle-Weak: telescoping, appetizing, educated, helicopter;

Strong-Weak-Weak-Middle: counterattack, capitalize;

Middle-Weak-Weak-Strong: aquamarine, photogravure;

Weak-Middle-Weak-Strong: misrepresent, misunderstand.

\section{Five Syllables:}

Weak-Middle-Weak-Strong-Weak: affiliation, consideration, apotheosis;

Middle-Weak-Weak-Strong-Weak: antimacassar, circumlocution, interdependence;

Middle-Weak-Strong-Weak-Weak: satisfactory, objectivity, aristocracy;

Middle-Weak-Strong-Weak-Middle: rehabilitate, inexactitude, incapacitate;

Weak-Strong-Weak-Weak-Weak: Catholicism, administrative, empiricism.

\section{Six Syllables:}


Weak-Middle-Weak-Strong-Weak-Weak: inferiority, impossibility, convertibility;

Middle-Weak-Weak-Strong-Weak-Weak: characteristically, variability, meteorological;

Middle-Weak-Strong-Weak-Weak-Weak: uncooperative, ceremoniously, indistinguishable;

Middle-Weak-Weak-Weak-Strong-Weak: palatalization, nationalization, autobiographic;

Weak-Middle-Weak-Weak-Strong-Weak: personification, identification, electrification.

Seven Syllables:

Middle-Weak-Strong-Weak-Weak-Weak-Weak: unilateralism;

Middle-Weak-Middle-Weak-Strong-Weak-Weak: unreliability;

Weak-Middle-Weak-Strong-Weak-Weak-Weak: enthusiastically;

Weak-Middle-Weak-Weak-Weak-Strong-Weak: industrialization;

Weak-Middle-Weak-Weak-Strong-Weak-Weak: impenetrability.

Eight syllables:

Middle-Weak-Middle-Weak-Weak-Weak-Strong-Weak: internationalization (A. C. Gimson, 1972: pp. 228230) [2].

\section{The stress patterns of compound words}

Most of the compound words in English are composed of two elements. Their stress patterns are as follows:

a) Stress falls on the first element of compound nouns, compound adjectives, compound adverbs and verbs:

Compound nouns: 'airport, 'blackboard, 'classroom, 'newspaper;

Compound adjectives and adverbs: 'outdoor, 'downstairs, 'worldwide, 'easy-going;

Compound verbs: 'baby-sit, 'hitch-hike, 'daydream, 'brainwash.

Besides, stress always falls on the first elements of the compound words consisting of every, any, some and no:

'Everyone, 'everybody, 'everything, 'everywhere, 'everyday, 'anyone, 'anybody, 'anything, 'anyhow, 'anywhere, 'someone, 'somebody, 'something, 'somehow, 'sometime(s), 'nobody, 'nothing, 'nowhere.

b) For some compound words, most of which are native words in English, stress may falls on the second elements:

The second element is ever: for'ever, how'ever, so'ever, when'ever, wher'ever, who'ever;

The second element is self: your'self, my'self, him'self, her'self, it'self, our'selves, your'selves, them'selves;

The first element is with: with'draw, with'hold, with'in, with'out, with'stand.

c) Stress falls on both of the two elements:

Compound words consisting of two nouns and the first functions as an adjective: 'head'master, 'week'end, 'gold-'coin, 'church'yard;

Compound words with "over” or "under” as the first element: 'over'charge, 'over'done, 'over'work, 'under'charge, 'under'estimate, 'under'developed;

Exceptions: 'overboard, over'due, 'over'come, 'underbrush, 'underground, 'undercut.

d) Compound adjectives composed of adjectives or noun + pp as predicative have two stresses:

'absent-'minded, 'ill-'humored, 'hand-'made, 'wooden-'headed.

But, if they function as a noun modifier, there is only one stress on the first element:

an 'absent-minded professor, a 'hand-made present

e) Compound words with three elements may have their stress either on the first or second elements:

hot-'water-bottle, high-'water-mark, 'light-house-keeper

But if the compound noun consist of a preposition or a article, the stress falls on the content word.

'father-in-'law, com'mander-in-'chief

Words in English are usually polysyllabic. Many words have more than two syllables, and some words even have six or seven or even more syllables. For example, revolutionary, unreliability, internationalization. The stress may have three levels: primary stress, secondary stress and unstress, and the places of word stress are various. It may falls on the first, second , third or even fourth syllable, very complicated. For the purpose of rhythm, many polysyllabic words have a secondary stress.

Examples:

On the first syllable: 'secretary, 'military;

On the second syllable: com'ponent, a'bandon;

On the third syllable: eco'nomical, gene'ration;

On the fourth syllable: exami'nation, paticu'larity. 
The stress is closely related with the quality of vowels. Generally speaking, the quality of vowels is complete only in the stressed syllables; in the unstressed syllables, vowels are often weakened to /i/, /ə/, / / / . If the stress of a word is misplaced, the vowel would be mispronounced (T. F. Xu et al., 1985) [3].

Examples:

record ['rekəd] n. record [ri'kə:d ] v.

absent ['æbsənt] a. absent [əb'sent] v.

concert ['konsət] n. concert [kən'sərt] v.

\subsection{The Functions of Word Stress in English}

Word stress distinguishes compound nouns from noun phrases which have the same spellings. If the stress falls on the first element, than it is a compound word, otherwise it a noun phrase. For example:

'blackbird: a common European and American bird, the male of which is completely black;

black'bird: a bird that is black;

'greenhouse: a glass building used for growing plants that need warmth, light and protection;

green'house: a house that is painted green.

Word stress distinguishes part of speech and meanings. In English, there are quite a few words with same spelling can both function as verbs or nouns. For most verbs, the stress falls on the second syllable, while for the nouns, it falls on the first.

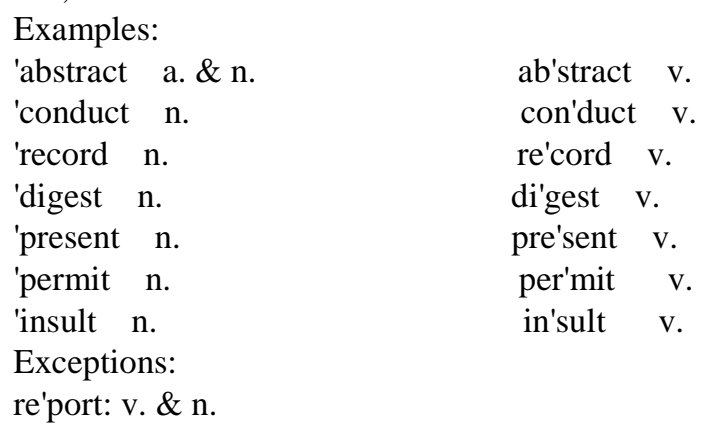

\subsection{The Features of the Word Stress Patterns in Sichuan Dialect}

The word stress patterns in Sichuan dialect are usually fixed and simple.

For most disyllabic words and phrases, word stress always falls on the first syllable.

The pattern is: Strong-Middle: '衣服, '但是, '果然, '快些, '漂亮, '学习.

For most words or phrases with three syllables, word stress always falls on the first syllable.

The pattern is: Strong-Middle-Middle: '电视机, '复印机, '李教授, '王老师, '桃花节, '牡丹花.

For most of the names of persons or places with three syllables, the first syllable is always stressed and lengthened, while for the names of persons with two syllables, the second syllable is lengthened and stressed (Liao Qing, 2005) [4].

For example:

Strong-Middle-Middle: '李晓霞, '刘凌峰, '凤凰山, '火车站, '办公室, '新西兰;

Middle-Strong: 肖'敏, 王'芳, 刘'刚, 陆'林, 张'建, 李'莉.

For most words or phrases with four syllables, word stress falls on the first and third syllables.

The pattern is:

Strong-Middle-Strong-Middle: '七嘴八舌, '乱七'八糟, '铺天'盖地, '横冲'直闯, '鸟语'花香, '香格'里拉.

For most verb phrases with three syllables, word stress always falls on the second syllable, and the first and third syllables are read weaker and shorter. The pattern is:

Middle-Strong-Middle:打'电脑, 洗'衣服, 剪'指甲, 盖'房子, 逛'商场, 看'报纸, 读'大学.

For words with more than four syllables, word stress usually falls on the first syllable and the following ones are less stressed. Most of them are names of foreign countries or persons.

The pattern is:

Strong-Middle-Middle -Middle: '巴基斯坦, '澳大利亚;

Strong-Middle-Middle-Middle-Middle: '加利福尼'亚, '印度尼西亚, '伊斯坦布尔; 
Strong-Middle-Middle-Middle-Middle-Middle: '美索'不达米亚;

Strong-Middle-Middle-Middle-Middle-Middle-Middle: '布宜诺斯艾利'斯.

Words in Sichuan dialect are usually disyllabic, trisyllabic, or quadrisyllable, only some foreign words have more than four syllables. The stress only has two levels: strong and middle, there are few unstressed syllables or toneless words in Sichuan dialect (Yuan Jiahua, 1983) [5].

The tone pitch of the stressed and lengthened syllable will change, usually higher than its original one. But not like that in English, word stress will not shift even in the continuous speech. The stressed syllable is always lengthened, which is a very unique phenomenon in Chinese dialects, particularly in Sichuan dialect.

In the continuous speech, the syllables before and after the stressed syllable are usually read short and fast, but the quality of vowels are still complete.

\subsection{The Functions of Word Stress in Sichuan Dialect}

Word stress distinguish meanings. In Sichuan dialect, some words or phrases may have the same pronunciation but different meanings, only word stress helps to distinguish their meanings. For example:

'晚点: (我晚点来) I will come a little later;

晚'点: (火车晚点了) The train is delayed;

'佣人: servant;

用人: choose a person for a job;

'大意: careless;

大'意: main points;

Word stress can help to form a new word.

In Sichuan dialect, stress can distinguish a compound word from a phrase which has the same pronunciation.

If the stress falls on the first element, it is a compound word, otherwise it a verb-object phrase.

Examples:

'佣人: servant;

用'人: choose a person for a job;

'晚点(儿): come (or go) a little later;

晚'点(火车、飞机等): (a bus, train or plane) delay;

'老丈: wife's father;

老'张: an address to an elder person whose family name is Zhang.

\section{The Similarities and Differences in Their Functions between English and Sichuan Dialect}

\subsection{Similarities}

Both in English and Sichuan dialect, stress can distinguish meaning. For example:

English'teacher: a teacher who teaches English;

'Englishteacher: a teacher who is an English;

paper'bag: a bag made of paper;

'paperbag: a waste paper collector;

re'cover: to get better after an illness, accident, shock, etc.;

re'cover: to put a new cover on a piece of furniture.

'佣人: servant

用'人: choose a person for a job

'晚点(儿): come (or go) a little later

晚'点(火车、飞机等): (a bus, train or plane) delay;

'老丈: wife' s father;

老'张: an address to an elder person whose family name is Zhang.

Both in English and Sichuan dialect, stress can help to form a new word.

Both in oral English and oral Sichuan dialect, stress can distinguish a compound word from a phrase which has the same spelling. If the stress falls on the first element, than it is a compound word, otherwise it a verb-object phrase. For example: 
'turn-key: a prison guard (a compound word);

turn'key: to move the key around so as to close/open the door (a verb-object phrase);

'show-case: a display cabinet (a compound word);

show'case: to prove the facts (a verb-object phrase);

'拉手: the handle on the door (a compound word);

拉'手: shake hands with sb. (a verb-object phrase);

下水: animal giblets (a compound word);

下'水: enter the water (a verb-object phrase).

\subsection{Differences}

In oral English, word stress can help to distinguish a compound noun from a noun phrase, but in Sichuan dialect, it does not have this function.

In English, the "adjective + noun" combination can be either a compound word or a noun phrase. If the stress falls on the first element of the combination, it is compound indicating a new idea entirely different from the meaning of the original combination. If the stress falls on the second element, then it is a noun phrase in which the first element modifies the second. In standard Chinese "Putonghua", word stress has the same function, but in Sichuan dialect it doesn't. In these cases, listeners have to judge the meaning of the speakers from the context.

Example:

'blackbird: a common European and American bird, the male of which is completely black;

black'bird: a bird that is black;

'greenhouse: a glass building used for growing plants that need warmth, light and protection;

green'house: a house that is painted green;

'大意: (a compound) main idea;

'大意: (a phrase) careless;

'大人: (a compound) a respectful address for an officer, particularly in the old time;

'大人: (a phrase) a grown-up.

Stress in English can distinguish the part of speech of a word, but in Sichuan dialect, it can't.

There are many disyllabic words in English which have the same spelling but different part of speech and even different meaning. In oral English, speakers have to use word stress to distinguish them. In most cases, it is a noun or an adjective if the stress falls on the first syllable, otherwise it is a verb.

Examples:

'abstract a. ab'stract v.

'conduct n. con'duct v.

'record n. re'cord v.

'digest n. di'gest $v$.

'present n. pre'sent v.

'permit n. per'mit v.

'insult n. in'sult v.

Exceptions:

report: v. \& n.

In Sichuan dialect, there are also some disyllabic words which can be either a noun or a verb, but the stress always falls on the first syllable.

Examples:

'通知 v. to notify or to inform

'通知 n. notice; notification; message

'练习 v. practise

'练习 n. practice; exercise

'报告 v. report; inform

'报告 n. report; speech; lecture

'把握 v. grasp; hold; seize

'把握 n. assurance; confidence; certainty

Word stress plays a very important role in English rhythm, while in Sichuan dialect, word stress is not such 
important. Rhythm in English is stress-timed, "the rhythmic beats of an utterance occur at fairy equal intervals of time. As a result of this, the speed at which the unstressed syllables are uttered—and the length of each—will depend upon the number occurring between the strong beats. All the unaccented syllables occurring between two strong beats may not, however, be uttered with equal rapidity: those following the strong beat of a rhythmic group tend to occupy slightly more time than those which precede the strong beat” (A. C. Gimson, p. 261) [2].

Chinese is syllable-timed, so is Sichuan dialect. The length of time of uttering a sentence depends on the number of syllables instead of the number of stressed syllables. In other words, the more the syllables there are, the longer the time is needed. In addition, nearly each word in Sichuan dialect is stressed.

\section{Conclusions}

From the analysis above, we can see that although both English and Chinese belong to free stress languages, most of the English words are polysyllabic, and their composition are complicated, besides, its vocabulary is mixed with a large number of foreign words, thereby causing the complexity and irregularity of the English word stress patterns. In contrast, most words in Sichuan dialect are disyllabic and only some are trisyllabic or more than three syllables, thus the word stress patterns in Sichuan dialect are much simpler than English. In addition, judging from the functions of word stress, it plays a more important role in English than in Sichuan dialect, which can not only distinguish meanings and differentiate compound words from adjective phrases, but also discriminate the part of speech of some disyllabic words with the same spelling.

For students in Sichuan, before learning English, they have already learned the sound system of their mother tongue, so they tend to stress each word when they speak Sichuan dialect. Due to the fact that the accentual patterns in Sichuan dialect are comparatively fixed and simpler than those in English, it is common for them to misplace word stress and sometimes even mispronounce English words. If English learners pay more attention to the differences and similarities between English and Sichuan dialect, there might be less word stress misplacements in their speech.

\section{Acknowledgements}

My paper is sponsored by “Sichuan Foreign Languages \& Cultures Center (四川外国语言文学研究中心)”.

\section{References}

[1] Xi, X.M. (1990) Comparison on the Word Stress of English and Chinese. Journal of Xi'an Foreign Language University, No. 1, 33-41.

[2] Gimson, A.C. (1972) An Introduction to the Pronunciation of English. Latimer Trend \&Co. Ltd., London.

[3] Xu, T.F., Yu, X.M. and Sun, W.B. (1985) Modern English Phonetics. Shanxi People Publishing House, Xi'an.

[4] Liao, Q. (2005) Research on Phenomenon of the Extended Word Stress in Chengdu Dialect. Journal of Deyang College of Education, No. 3, 15-16.

[5] Yuan, J.H. (1983) An Introduction to Chinese Dialects. 2nd Edition, Writing System Reform Press, Beijing. 